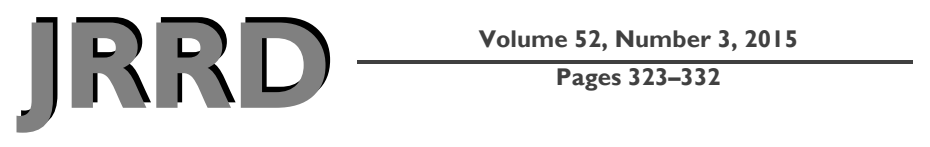

\title{
Effects of Kinesio Tape application to quadriceps muscles on isokinetic muscle strength, gait, and functional parameters in patients with stroke
}

\author{
Timur Ekiz, MD; ${ }^{*}$ Meryem Doğan Aslan, MD; Neşe Özgirgin, MD \\ Department of Physical Medicine and Rehabilitation, Ankara Physical Medicine and Rehabilitation Education and \\ Research Hospital, Ankara, Turkey
}

\begin{abstract}
The aim of this study was to evaluate the effects of Kinesio Tape (KT) application to quadriceps muscles on isokinetic muscle strength, gait, and functional parameters in patients with stroke. Twenty-four patients were allocated into KT and control groups. All patients participated in the same conventional rehabilitation program 5 times/wk for 4 wk. In addition, KT was applied to quadriceps muscles bilaterally to the patients in the KT group. Compared with baseline, peak torque levels increased significantly in both groups (all $p<$ $0.05)$. However, change levels were significantly higher in the KT group than the control group at 60 degrees/second angular velocity $(\mathrm{AV})$ in extension $(p=0.04)$ and 60 and 180 degrees/ second AV in flexion (both $p=0.02$ ) on the paretic side. Moreover, the change levels were more prominent in the KT group at 60 and 180 degrees/second $\mathrm{AV}$ in extension $(p=0.03$ and $p=0.04$, respectively) on the nonparetic side. Gait, balance, mobility, and quality of life values improved significantly in both groups (all $p<0.05$ ), yet the change levels between the groups did not reach significance $(p>0.05)$. KT application to quadriceps muscles in addition to conventional exercises for $4 \mathrm{wk}$ is effective on isokinetic but not functional parameters.
\end{abstract}

Key words: cerebrovascular disorders, gait, isokinetic, Kinesio Tape, Kinesio Taping, muscle strength, peak torque, quadriceps muscle, quality of life, rehabilitation, stroke.

\section{INTRODUCTION}

Kinesio $^{\circledR}$ Tape (KT) has been widely used as an alternative therapy in people with several musculoskele- tal disorders, those engaged in sports or neurological rehabilitation, and those with lymphedema because of its advantages (aesthetic, comfort, ease of application, and lack of side effects [aside from skin reactions]) [1-2]. It has been previously documented that KT enhances muscle activation and reeducation by increasing the subcutaneous space, enhancing blood flow, and providing tactile stimulation [1-2].

Effects of KT on muscle strength have been studied in nondisabled subjects and subjects with knee osteoarthritis, yet the results of these studies are conflicting [3-11]. Furthermore, previous studies focused on short-term effects of KT application. Effects of long-term KT application have not yet been studied. Effects of KT on muscle strength in patients with stroke have also not been studied.

\footnotetext{
Abbreviations: 6MWT $=6$-minute walk test, $10 \mathrm{MWT}=10$ meter walk test, $\mathrm{AV}=$ angular velocity, $\mathrm{BBS}=$ Berg Balance Scale, $\mathrm{BMI}=$ body mass index, $\mathrm{FAC}=$ Functional Ambulation Category, FIM $=$ Functional Independence Measure, KT = Kinesio $^{\circledR}$ Tape, MAS $=$ Modified Ashworth Scale, PT $=$ peak torque, RMI = Rivermead Mobility Index, SCT = Stair-Climbing Test, SS-QLS = Stroke-Specific Quality of Life Scale, TUG = Timed "Up and Go" test.

"Address all correspondence to Timur Ekiz, MD; Department of Physical Medicine and Rehabilitation, Ankara Physical Medicine and Rehabilitation Education and Research Hospital, Türkocağı Sok. No: 3, Ankara 06230, Turkey; +90-312-310-3230; fax: +90-312-311-8054.

Email: timurekiz@gmail.com http://dx.doi.org/10.1682/JRRD.2014.10.0243
} 
Accordingly, the objective of this study was to evaluate the effects of long-term KT application to quadriceps muscles on isokinetic muscle strength, gait, and functional parameters in patients with stroke. Moreover, KT was applied bilaterally in our study to allow us to compare the effects of KT on the paretic and nonparetic sides.

\section{METHODS}

\section{Study Design}

A total of 24 patients with subacute, chronic stroke were allocated into KT and control groups. The subjects participated in the same conventional rehabilitation program, including neurophysiologic exercises, range-ofmotion exercises, posture training, walking training, and balance coordination training 5 times/wk for $4 \mathrm{wk}$. In addition, KT was applied to quadriceps muscles bilaterally to the participants in the KT group for $4 \mathrm{wk}$. All patients were evaluated before and after the treatment with respect to isokinetic muscle strength, balance, gait, mobility, and quality of life.

\section{Participants}

Patients with stroke who participated in an inpatient rehabilitation program in our rehabilitation center between June 2013 and June 2014 were enrolled.

Exclusion criteria were not cooperative, history of previous stroke, severe cardiovascular or pulmonary problems, uncontrolled hypertension, hemiplegia due to trauma/tumor, severe aphasia (which could affect evaluations), cerebellar infarct, musculoskeletal pain or other lower-limb disorder (e.g., fracture, severe osteoarthritis), or KT allergy or skin lesions in lower limbs.

\section{Data Collection and Assessment Tests}

Demographic and clinical features of the patients such as age, sex, body mass index (BMI), paretic side, time poststroke, and stroke type (thromboembolism/hemorrhage) were noted. Brunnstrom stages were used to evaluate motor recovery. Spasticity levels were assessed by the Modified Ashworth Scale (MAS). Ambulation levels were evaluated by the Functional Ambulation Category (FAC). Functional parameters, quality of life, gait parameters, mobility, and balance parameters of all patients were assessed by the Functional Independence Measure (FIM) Motor scale, Stroke-Specific Quality of Life Scale (SS-QLS), Timed "Up and Go" test (TUG), 10-meter walk test (10MWT), 6-minute walk test (6MWT), Stair-Climbing Test (SCT), Berg Balance Scale (BBS), and Rivermead Mobility Index (RMI).

\section{Isokinetic Test Protocol}

Peak and average isokinetic torque can be reliably used for assessing muscle strength of the lower limbs in patients with stroke [12-13]. The Biodex System 3 Pro multijoint isokinetic dynamometer (Biodex Medical Systems; Shirley, New York) was used to assess muscle strength in our study. All participants were informed about the test procedure to achieve maximum orientation.

The patients were seated in a reclined position $\left(85^{\circ}\right.$ from the horizontal plane). A hip-waist belt, a cross-trunk belt, and a Velcro strap across the thighs were used for stabilization. The dynamometer was adjusted according to the line passing through the femoral condyles. The dynamometer effort arm was adjusted according to the length of the leg. The leg was fixed (over the lateral malleolus) by using a pad (Figure 1). Range of motion was set individually according to the active range of motion of the patients. Three submaximal trial repetitions were performed at both angular velocities (AVs) (60 and 180\%) before the test. Power graphics were shown on the monitor to provide visual feedback. The isokinetic test protocol was 5 maximal reciprocal contractions at $60 \% \mathrm{sV}$,

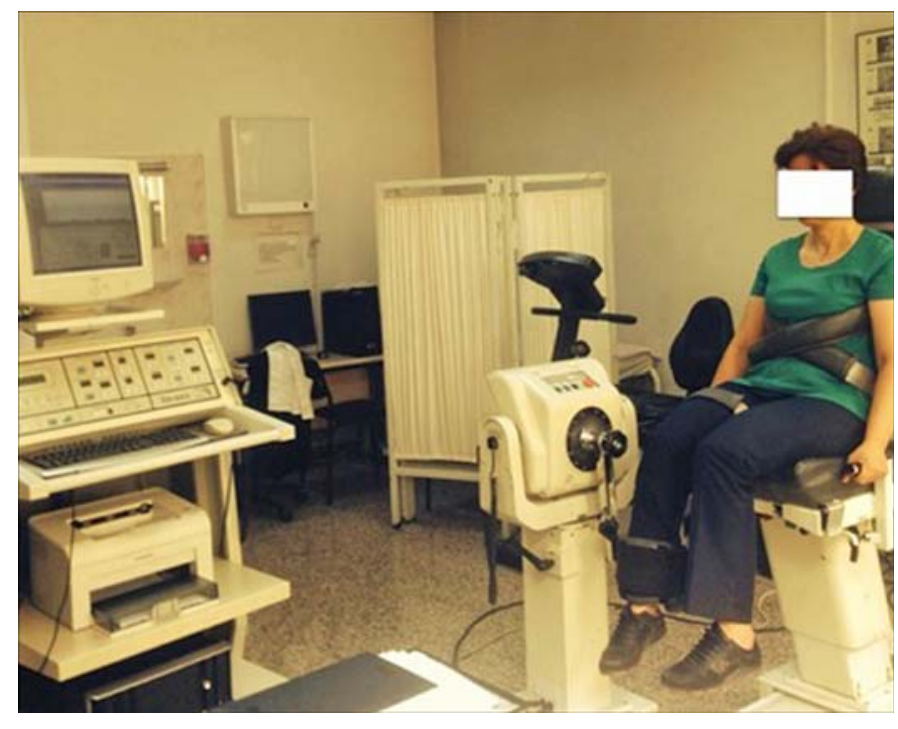

Figure 1.

Isokinetic muscle strength measurement setup. 
$15 \mathrm{~s}$ rest period, then 10 maximal reciprocal contractions at $180 \% \mathrm{~s} \mathrm{AV}$.

\section{Kinesio Taping}

KT (Kinesio Tex Gold, Kinesio ${ }^{\circledR}$; Albuquerque, New Mexico) was applied to the vastus medialis, vastus lateralis, and rectus femoris muscles bilaterally using the muscle stimulation technique (from origin to insertion without tension) in Kase et al. [1]. Subjects wore the tape for $4 \mathrm{wk}$, and it was changed every 3-7 d. All tapes were prepared individually as "Y-bands." The edges of the bands were squared.

For the rectus femoris muscle, the tape was applied from $10 \mathrm{~cm}$ below the anterior superior iliac spine to the superior edge of the patella (without tension). Then, the tape was crossed from the edges of the patella (with maximum tension) and fixed below the inferior edge of the patella while the knee was flexed. For the vastus lateralis muscle, the tape was applied from the great trochanter to the lateral edge of the patella (without tension). The tape was then crossed from the lateral edge of the patella (with maximum tension) and fixed below the inferior edge of the patella while the knee was in flexed position, and then another piece of tape was fixed over the fibular head. For the vastus medialis muscle, KT was applied from the middle third of the medial thigh to the medial edge of the patella (without tension). Next, the tape was crossed from the medial edge of the patella (with maximum tension). Finally, another piece of tape was fixed over the tibia (Figure 2).

\section{Functional Independence Measure}

The FIM is composed of 18 items. While 13 of the items assess motor tasks, 5 assess cognitive tasks. In this study, FIM Motor scores were used. Motor items mainly include self-care activities, sphincter control, transfers, and locomotion. Each item is scored from 1 to 7 , and higher scores demonstrate better functioning. FIM is valid and reliable for assessing functionality in patients with stroke [14].

\section{Rivermead Mobility Index}

RMI is a valid and reliable test for subacute, chronic stroke that is used for assessing functional mobility such as gait, balance, and transfers. The RMI includes the following items: turning over in bed, lying to sitting, sitting balance, sitting to standing, standing, transferring, walking inside/outside, climbing stairs, picking up off floor,

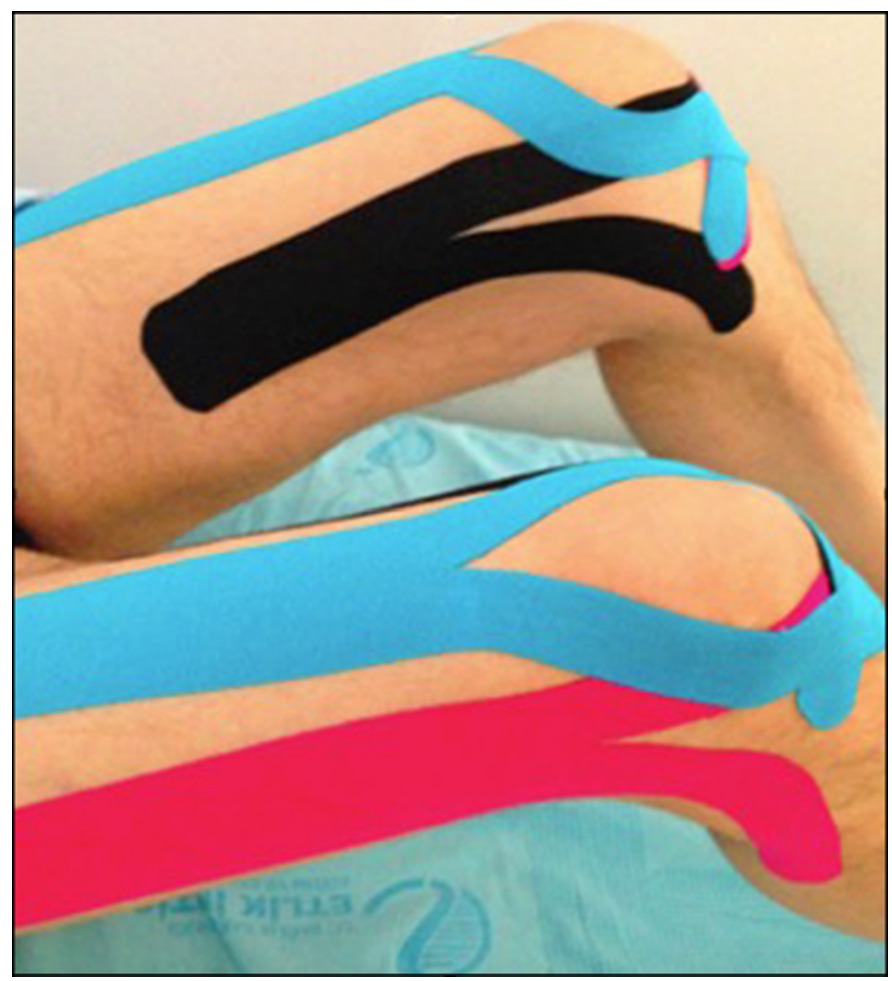

Figure 2.

Kinesio Tape application to vastus medialis, vastus lateralis, and rectus femoris muscles.

climbing up and down four steps, and running. Each item is scored 0 or 1 . Higher scores show better mobility performance. RMI has been previously reported to be a useful scale for the assessment of mobility in patients with stroke [15].

\section{Timed "Up and Go" Test}

Subjects were asked to stand up from a chair with an armrest, walk $3 \mathrm{~m}$ at a comfortable and safe walking speed, turn around, and sit down. The time required to carry out this task was measured. The TUG can be used for measuring basic mobility skills after stroke [16].

\section{6-Minute Walk Test}

6MWT assesses endurance. The subjects were instructed to walk (at their preferred speed) through a corridor (flat surface), and the distances walked in $6 \mathrm{~min}$ were measured. Subjects were allowed to use assistive devices. 6MWT is reliable for patients with stroke [17]. 


\section{0-Meter Walk Test}

This test is used to assess walking speed. Subjects are instructed to walk $10 \mathrm{~m}$ without personal assistance. The time is measured for the middle $6 \mathrm{~m}$. An average of three repetitions was calculated. 10MWT is valid and reliable for patients with stroke [18].

\section{Berg Balance Scale}

BBS assesses static balance. It has the following items: reaching forward with an outstretched arm, standing with eyes closed with one foot in front, turning, retrieving an object from the floor, standing on one foot, sitting to stand, turning $360^{\circ}$, standing, placing the alternate foot on a stool, transferring, standing with feet together, and standing to sitting unsupported. Each item was scored from 0 to 4 . The maximum score is 56 . Higher BBS scores indicate better balance. BBS is valid and reliable for patients with stroke [19].

\section{Stroke-Specific Quality of Life Scale}

SS-QLS includes 49 items. The major items are energy, family roles, language, mobility, mood, personality, self-care, social roles, thinking, upper-limb function, vision, and work/productivity. Each item is scored from 1 to 5 . Higher scores show better functioning [20].

\section{Functional Ambulation Category}

The FAC classifies ambulation of patients into six levels:

0 . Nonfunctional, ambulates only with parallel bars.

1. Ambulates with continuous manual contact of one person.

2. Ambulates with light touch of one person.

3. Ambulates without touch but with supervision.

4. Ambulates independently on level surfaces, but not on stairs.

5. Ambulates independently on stairs and unlevel surfaces [21].

\section{Stair-Climbing Test}

The SCT is a tool used for assessing ascending and descending stairs. A four-step ascend and descend was used, and duration to finish a set was recorded. Lower values of SCT show better performance [22].

\section{Statistical Analysis}

The data was analyzed with SPSS for Windows (IBM; Armonk, New York). A Shapiro-Wilk test was used to determine whether the continuous variables were normally distributed. Descriptive statistics are shown as mean \pm standard deviation or median (minimum, maximum).

The comparison of the means and medians of the groups was completed with a Student $t$-test. Categorical variables were analyzed by Pearson chi-square or Fisher exact tests. A Wilcoxon signed rank test was used if there was a significant difference before and after the treatment in the groups. A $p$-value of $<0.05$ was considered statistically significant.

\section{RESULTS}

Demographic and clinical features of the groups are shown in Table 1. The groups were similar with respect to age, sex, BMI, paretic side, Brunnstrom stages, FAC, time poststroke, and MAS (all $p>0.05$ ). By contrast, there was a significant difference between the groups for stroke etiology $(p=0.03)$. In the KT group, 8 patients had thromboembolic stroke and 4 patients hemorrhagic stroke, and in the control group, 12 patients had thromboembolic stroke.

Paretic side peak torque (PT) values of each group before and after treatment are shown in Table 2. Compared with baseline, PT levels increased significantly in both groups after treatment (all $p<0.05$ ). However, change levels were significantly higher in the KT group than in the control group at $60 \% \mathrm{~s} \mathrm{AV}$ in extension $(p=$ 0.04 ) and 60 and $180 \%$ AVs in flexion (both $p=0.02$ ).

Nonparetic side PT values of each group before and after treatment are shown in Table 3. Although PT values increased significantly in both groups (all $p<0.05$ ), the change levels were more prominent in the KT group at 60 and $180 \%$ s AVs in extension $(p=0.03$ and $p=0.04$, respectively).

Gait, balance, mobility, quality of life, and functional parameters of the groups are shown in Table 4. Compared with baseline, all values increased significantly in both groups (all $p<0.05$ ); however, the change levels between the groups did not reach significance $(p>0.05)$. For side effects, a temporary skin reaction was seen in only one patient during the last application. 
Table 1.

Clinical and demographic features of study subjects. Data presented as mean \pm standard deviation or $n(\%)$.

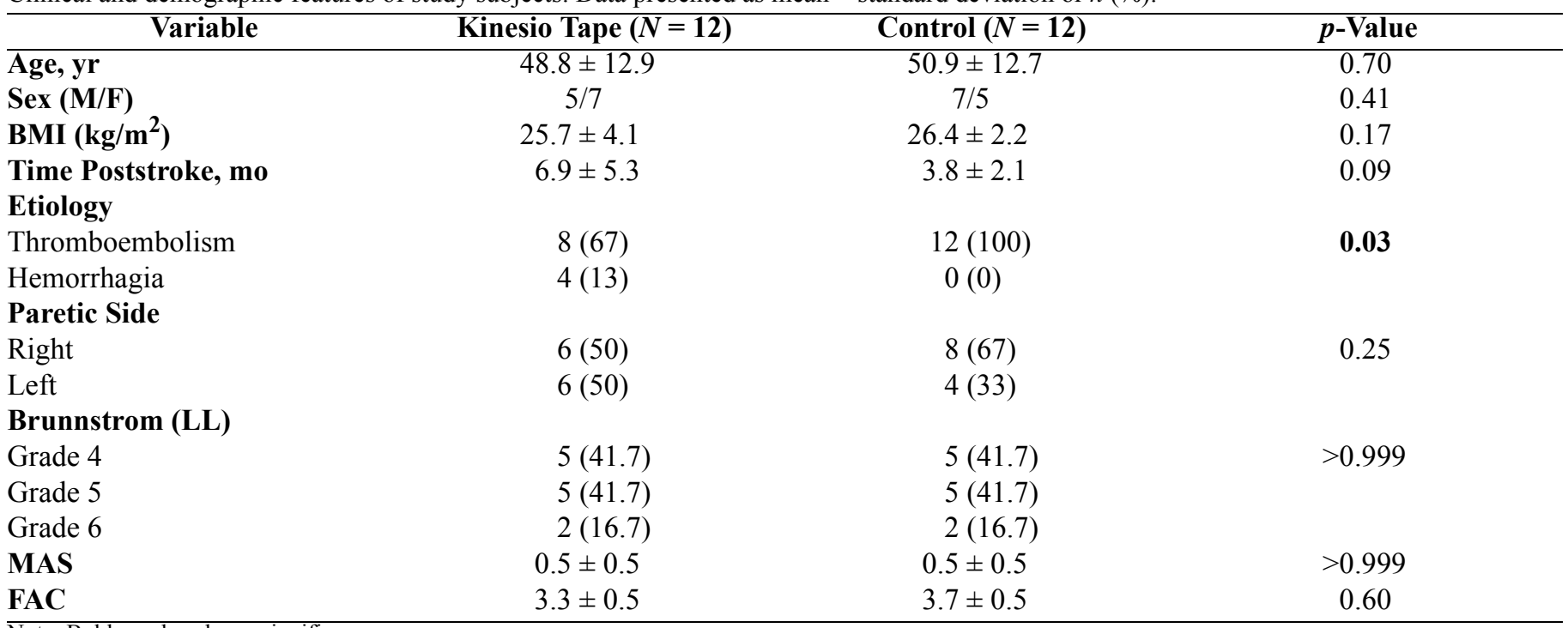

Note: Bold $p$-value shows significance.

$\mathrm{BMI}=$ body mass index, $\mathrm{F}=$ female, $\mathrm{LL}=$ lower limb, $\mathrm{M}=$ male, MAS = Modified Ashworth Scale, FAC $=$ Functional Ambulation Category.

Table 2.

Paretic side peak torque (PT) values before and after treatment and change levels between groups. Data presented as mean \pm standard deviation.

\begin{tabular}{|c|c|c|c|c|}
\hline Isokinetic Parameter & PT Before Treatment & PT After Treatment & Change Level & $p$-Value \\
\hline \multicolumn{5}{|l|}{$\overline{\text { Knee Extension 60\% }}$ AV } \\
\hline Control & $40.0 \pm 26.2$ & $47.7 \pm 29.5$ & $7.7 \pm 4.8$ & \\
\hline KT & $19.0 \pm 11.0$ & $29.5 \pm 16.3$ & $6.4 \pm 1.8$ & 0.02 \\
\hline Control & $12.1 \pm 8.0$ & $14.4 \pm 9.6$ & $1.9 \pm 0.5$ & \\
\hline Control & $25.5 \pm 7.0$ & $29.7 \pm 7.3$ & $4.4 \pm 1.6$ & \\
\hline \multicolumn{5}{|l|}{ Knee Flexion $180^{\circ} / \mathrm{s}$ AV } \\
\hline KT & $11.9 \pm 3.3$ & $18.7 \pm 7.1$ & $8.0 \pm 5.7$ & 0.02 \\
\hline Control & $14.7 \pm 9.5$ & $19.9 \pm 8.0$ & $3.5 \pm 1.8$ & \\
\hline
\end{tabular}

\section{DISCUSSION}

In this study, we aimed to elucidate, for the first time in the literature (to the best of our knowledge), whether bilateral KT application to quadriceps muscles is effective on isokinetic and functional parameters in patients with stroke. The most significant result of our study was that KT increased muscle strength on both the paretic and nonparetic sides, while functional parameters did not improve.
Kase et al. have reported that KT increases muscle activation through the following two mechanisms [1]. First, KT stimulates the cutaneous receptors by tactile stimulation, and second, KT increases the subcutaneous space and blood flow, both of which result in muscle activation. In the literature, there are several studies showing the effects of KT on muscle strength [2-11]; however, these studies have conflicting results. While some of the studies reported improvement in muscle strength $[9,11]$, others found adverse outcomes [3-8]. 
Table 3.

Nonparetic side peak torque (PT) values before and after treatment and change levels between groups. Data presented as mean \pm standard deviation.

\begin{tabular}{|c|c|c|c|c|}
\hline Isokinetic Parameter & PT Before Treatment & PT After Treatment & Change Level & $p$-Value \\
\hline \multicolumn{5}{|l|}{$\overline{\text { Knee Extension 60\% }}$ AV } \\
\hline $\mathrm{KT}$ & $64.1 \pm 26.5$ & $82.5 \pm 32.7$ & $17.7 \pm 10.0$ & 0.03 \\
\hline Control & $64.9 \pm 28.0$ & $73.9 \pm 27.3$ & $8.9 \pm 5.4$ & \\
\hline \multicolumn{5}{|l|}{ Knee Flexion $60 \%$ s AV } \\
\hline $\mathrm{KT}$ & $37.0 \pm 26.1$ & $43.0 \pm 26.3$ & $6.0 \pm 5.2$ & 0.60 \\
\hline Control & $24.6 \pm 13.5$ & $31.5 \pm 14.5$ & $6.9 \pm 2.4$ & \\
\hline $\mathrm{KT}$ & $44.2 \pm 22.2$ & $56.8 \pm 26.6$ & $12.5 \pm 9.0$ & 0.04 \\
\hline Control & $40.2 \pm 22.9$ & $46.0 \pm 23.9$ & $5.8 \pm 2.5$ & \\
\hline \multicolumn{5}{|l|}{ Knee Flexion $180 \%$ s AV } \\
\hline $\mathrm{KT}$ & $21.6 \pm 15.0$ & $28.0 \pm 17.2$ & $6.4 \pm 4.4$ & 0.19 \\
\hline Control & $15.0 \pm 4.6$ & $19.5 \pm 6.2$ & $4.4 \pm 2.4$ & \\
\hline
\end{tabular}

Table 4.

Gait, balance, mobility, and quality of life values before and after treatment and change levels between groups. Data presented as mean \pm standard deviation.

\begin{tabular}{|c|c|c|c|c|}
\hline Variable & Before Treatment & After Treatment & Change Level & $p$-Value \\
\hline \multicolumn{5}{|l|}{ FIM (Motor) } \\
\hline KT & $56.3 \pm 12.0$ & $63.6 \pm 10.9$ & $7.3 \pm 2.4$ & 0.93 \\
\hline Control & $70.2 \pm 6.0$ & $78.1 \pm 5.2$ & $7.4 \pm 1.8$ & \\
\hline \multicolumn{5}{|l|}{ SS-QLS } \\
\hline KT & $158.9 \pm 23.6$ & $170.9 \pm 22.1$ & $3.4 \pm 1.0$ & 0.44 \\
\hline Control & $149.0 \pm 18.8$ & $161.2 \pm 19.3$ & $2.2 \pm 0.6$ & \\
\hline KT & $15.7 \pm 3.8$ & $12.1 \pm 2.6$ & $1.5 \pm 0.5$ & 0.29 \\
\hline Control & $18.1 \pm 6.4$ & $15.3 \pm 5.3$ & $1.8 \pm 0.5$ & \\
\hline \multicolumn{5}{|l|}{ 6MWT } \\
\hline KT & $284.0 \pm 73.5$ & $309.8 \pm 68.9$ & $19.5 \pm 8.9$ & 0.60 \\
\hline Control & $211.6 \pm 85.4$ & $233.7 \pm 84.0$ & $9.1 \pm 2.6$ & \\
\hline \multicolumn{5}{|l|}{ TUG } \\
\hline KT & $15.5 \pm 3.3$ & $12.3 \pm 2.7$ & $1.3 \pm 0.4$ & 0.21 \\
\hline Control & $17.5 \pm 8.3$ & $15.2 \pm 6.7$ & $1.9 \pm 0.5$ & \\
\hline \multicolumn{5}{|l|}{ BBS } \\
\hline KT & $30.2 \pm 8.0$ & $35.1 \pm 7.8$ & $4.9 \pm 3.3$ & 0.51 \\
\hline Control & $46.5 \pm 4.5$ & $50.8 \pm 3.4$ & $4.1 \pm 1.9$ & \\
\hline \multicolumn{5}{|l|}{ RMI } \\
\hline KT & $9.4 \pm 3.1$ & $11.5 \pm 3.8$ & $1.9 \pm 1.1$ & 0.06 \\
\hline Control & $11.2 \pm 1.6$ & $12.3 \pm 1.1$ & $1.0 \pm 0.9$ & \\
\hline
\end{tabular}


Wong et al. evaluated the effects of KT application to quadriceps muscle in nondisabled subjects [5]. Although total work and PT values did not change in their study, time to PT decreased significantly. In a controlled trial by Lins et al., 60 nondisabled patients were randomized into $\mathrm{KT}$, elastic bandage, and control groups [6]. KT was applied to vastus medialis, vastus lateralis, and rectus femoris muscles in the KT group. However no significant differences were found after application in isokinetic, postural balance, or functional parameters. Moreover, in a single-blind, placebo-controlled, crossover study by Vercelli et al., 36 nondisabled subjects were randomized into three groups as follows: KT with stimulation technique, KT with inhibition technique, and sham band [8]. Isokinetic parameters did not change in any of the three groups. Anandkumar et al. randomized 40 patients with knee osteoarthritis into control and KT groups and found that posttest isokinetic parameters and pain scale scores showed statistical improvement [11]. Fratocchi et al. have shown significant improvement in PT values of biceps brachii muscles in the KT group versus the placebo band group [9].

In our study, we enrolled patients with hemiplegia who were in a rehabilitation program, which is different from the previous studies. In addition, we applied KT bilaterally in order to compare the paretic and nonparetic sides. Regarding the time frame, we evaluated long-term effects rather than short-term effects. All isokinetic parameters showed improvement in both groups after the treatment $(p<0.05)$; however, the increases were more prominent in the KT group. Stroke duration was shorter in the control group $(p<0.05)$. We could speculate that paretic muscles have more sensitivity to tactile stimulation and muscle reeducation than nonparetic muscles.

Another important issue in our study was the increase in the flexion parameter. Although we applied KT only to extensor muscles, flexor muscles showed improvement on the paretic side as well. We could attribute this result to the fact that the strengthening in the knee extensors and the mechanical support of KT contribute to better knee control. On the other hand, the increase in isokinetic parameters did not result in improvement of functional parameters and gait. This could have been because muscle strength did not develop enough or because functional parameters are related to several other factors, such as proprioception and balance. Also, KT may need to be applied for longer periods.
As for side effects, a skin reaction was seen only in one patient. It was temporary and seen only during the last application (at the end of the fourth week). We did not find any side effects that could have discontinued rehabilitation, caused discomfort, or affected activities of daily living. We did not use a satisfaction scale in our study. Nonetheless, we received positive feedback from the patients regarding the KT application. For instance, some patients stated that they could feel mechanical support and perform knee extension better. We believe that this can result in better motivation and self-confidence during the rehabilitation process.

\section{LIMITATIONS}

First, our sample size could have been larger. Although the groups were similar regarding age, BMI, sex, and functional parameters, stroke patients show heterogeneity. Second, lack of a crossover design and follow-up evaluations are limitations of our study. Third, the selection bias of patients who had high levels of function according to Brunnstrom grading is a limitation as well. However, it would not be possible to perform this study on patients with low levels of functioning.

\section{CONCLUSIONS}

In light of our results, KT application to quadriceps muscles in addition to conventional exercises for $4 \mathrm{wk}$ seems to be effective on isokinetic parameters on the paretic and nonparetic side, but not on functional parameters. Crossover and long-term follow-up studies regarding the effects of KT on muscle strength or proprioception are awaited.

\section{ACKNOWLEDGMENTS}

\section{Author Contributions:}

Study concept and design: T. Ekiz, M. Doğan Aslan, N. Özgirgin. Acquisition of data: T. Ekiz.

Drafting of manuscript: T. Ekiz, M. Doğan Aslan, N. Özgirgin. Critical revision of manuscript for important intellectual content: M. Doğan Aslan, N. Özgirgin. Statistical analysis: T. Ekiz.

Study supervision: N. Özgirgin.

Financial Disclosures: The authors have declared that no competing interests exist. 
Funding/Support: This study was unfunded at the time of manuscript preparation.

Institutional Review: The study protocol was approved by the Ankara Physical Medicine and Rehabilitation Education and Research Hospital Ethics Committee, and informed consent was obtained from the participants.

Participant Follow-Up: The authors do not plan to notify participants of the publication of this article.

\section{REFERENCES}

1. Kase K, Wallis J, Kase T. Clinical therapeutic application of the kinesio taping method. Tokyo (Japan): Ken Ikai Co Ltd; 2003.

2. Çeliker R, Güven Z, Aydoğ T, Bağış S, Atalay A, Çağlar Yağcı H, Korkmaz N. [The Kinesiologic Taping technique and its applications]. Turk J Phys Med Rehab. 2011; 57(4):225-35. Turkish.

http://dx.doi.org/10.4274/tftr.46548

3. Chang HY, Chou KY, Lin JJ, Lin CF, Wang CH. Immediate effect of forearm Kinesio taping on maximal grip strength and force sense in healthy collegiate athletes. Phys Ther Sport. 2010;11(4):122-27. [PMID:21055705] http://dx.doi.org/10.1016/j.ptsp.2010.06.007

4. Aktas G, Baltaci G. Does kinesiotaping increase knee muscles strength and functional performance? Iso Exerc Science. 2011;3:149-55.

5. Wong OM, Cheung RT, Li RC. Isokinetic knee function in healthy subjects with and without Kinesio taping. Phys Ther Sport. 2012;13(4):255-58. [PMID:23068902] http://dx.doi.org/10.1016/j.ptsp.2012.01.004

6. Lins CA, Neto FL, Amorim AB, Macedo LB, Brasileiro JS. Kinesio Taping $\left({ }^{\circledR}\right)$ does not alter neuromuscular performance of femoral quadriceps or lower limb function in healthy subjects: Randomized, blind, controlled, clinical trial. Man Ther. 2013;18(1):41-45. [PMID:22796389]

http://dx.doi.org/10.1016/j.math.2012.06.009

7. Fu TC, Wong AM, Pei YC, Wu KP, Chou SW, Lin YC. Effect of Kinesio taping on muscle strength in athletes-a pilot study. J Sci Med Sport. 2008;11(2):198-201. [PMID:17588814] http://dx.doi.org/10.1016/j.jsams.2007.02.011

8. Vercelli S, Sartorio F, Foti C, Colletto L, Virton D, Ronconi G, Ferriero G. Immediate effects of kinesiotaping on quadriceps muscle strength: A single-blind, placebo-controlled crossover trial. Clin J Sport Med. 2012;22(4):319-26. [PMID:22450591] http://dx.doi.org/10.1097/JSM.0b013e31824c835d

9. Fratocchi G, Di Mattia F, Rossi R, Mangone M, Santilli V, Paoloni M. Influence of Kinesio Taping applied over biceps brachii on isokinetic elbow peak torque. A placebo controlled study in a population of young healthy subjects.
J Sci Med Sport. 2013;16(3):245-49. [PMID:22771110]

http://dx.doi.org/10.1016/j.jsams.2012.06.003

10. Alexander CM, McMullan M, Harrison PJ. What is the effect of taping along or across a muscle on motoneurone excitability? A study using triceps surae. Man Ther. 2008; 13(1):57-62. [PMID:17188548] http://dx.doi.org/10.1016/j.math.2006.08.003

11. Anandkumar S, Sudarshan S, Nagpal P. Efficacy of kinesio taping on isokinetic quadriceps torque in knee osteoarthritis: A double blinded randomized controlled study. Physiother Theory Pract. 2014;30(6):375-83. [PMID:24617598] http://dx.doi.org/10.3109/09593985.2014.896963

12. Eng JJ, Kim CM, Macintyre DL. Reliability of lower extremity strength measures in persons with chronic stroke. Arch Phys Med Rehabil. 2002;83(3):322-28. [PMID:11887111] http://dx.doi.org/10.1053/apmr.2002.29622

13. Hsu AL, Tang PF, Jan MH. Test-retest reliability of isokinetic muscle strength of the lower extremities in patients with stroke. Arch Phys Med Rehabil. 2002;83(8):1130-37. [PMID:12161836] http://dx.doi.org/10.1053/apmr.2002.33652

14. Küçükdeveci AA, Yavuzer G, Elhan AH, Sonel B, Tennant A. Adaptation of the Functional Independence Measure for use in Turkey. Clin Rehabil. 2001;15:311-19. [PMID:11386402]

15. Hsieh CL, Hsueh IP, Mao HF. Validity and responsiveness of the rivermead mobility index in stroke patients. Scand J Rehabil Med. 2000;32(3):140-42. [PMID:11028799] http://dx.doi.org/10.1080/003655000750045497

16. Hafsteinsdóttir TB, Rensink M, Schuurmans M. Clinimetric properties of the Timed Up and Go Test for patients with stroke: A systematic review. Top Stroke Rehabil. 2014; 21(3):197-210. [PMID:24985387] http://dx.doi.org/10.1310/tsr2103-197

17. Fulk GD, Echternach JL, Nof L, O’Sullivan S. Clinometric properties of the six-minute walk test in individuals undergoing rehabilitation poststroke. Physiother Theory Pract. 2008;24(3):195-204. [PMID:18569856] http://dx.doi.org/10.1080/09593980701588284

18. Flansbjer UB, Holmbäck AM, Downham D, Patten C, Lexell J. Reliability of gait performance tests in men and women with hemiparesis after stroke. J Rehabil Med. 2005;37(2):75-82. [PMID:15788341] http://dx.doi.org/10.1080/16501970410017215

19. Sahin F. Reliability and validity of Turkish version of the Berg Balance Scale in patients with stroke. Turk J Phys Med Rehabil. 2013;59:170-75.

20. Hakverdioğlu Yönt G, Khorshid L. Turkish version of the Stroke-Specific Quality of Life Scale. Int Nurs Rev. 2012; 59(2):274-80. [PMID:22591101] http://dx.doi.org/10.1111/j.1466-7657.2011.00962.x 
21. Mehrholz J, Wagner K, Rutte K, Meissner D, Pohl M. Predictive validity and responsiveness of the functional ambulation category in hemiparetic patients after stroke. Arch Phys Med Rehabil. 2007;88(10):1314-19. [PMID:17908575] http://dx.doi.org/10.1016/j.apmr.2007.06.764

22. Harries N, Loeppky JA, Shaheen S, Al-Jarrah M, Molteni F, Hutzler Y, Bar-Haim S; MESF Project. A stair-climbing test for measuring mechanical efficiency of ambulation in adults with chronic stroke. Disabil Rehabil. 2015;37(11): 1004-8. [PMID:25113573]

http://dx.doi.org/10.3109/09638288.2014.948131

Submitted for publication October 19, 2014. Accepted in revised form February 24, 2015.
This article and any supplementary material should be cited as follows:

Ekiz T, Doğan Aslan M, Özgirgin N. Effects of Kinesio Tape application to quadriceps muscles on isokinetic muscle strength, gait, and functional parameters in patients with stroke. J Rehabil Res Dev. 2015;52(3): 323-32.

http://dx.doi.org/10.1682/JRRD.2014.10.0243

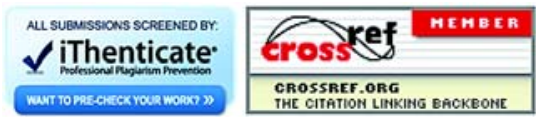


